\title{
Zingerone ameliorates tellurium induced nephrotoxicity by abating elevated serum markers in the rats
}

\author{
Alam Mohammad Firoz ${ }^{1} \bowtie$, Alshahrani Saeed ${ }^{1}$, Alamir Essam Ali ${ }^{1}$, Alhazmi Mohammad \\ Abdurrhman $^{1}$, Anwer Tarique ${ }^{1}$, Khan Gyas ${ }^{1}$, Moni Sivakumar Sivagurunathan ${ }^{2}$
}

Received: 09.04.2020

Revised: 28.04.2020

Accepted: 01.05.2020

\begin{abstract}
The present study was designed to investigate the nephrotoxicity of tellurium (Sodium tellurite) in rats through evaluating the level of kidney functional marker enzymes and its treatment with Zingerone. Rats were divided into four groups, Group-A (control group), Group-B (tellurium treated group), Group-C (tellurium + Zingerone treatment group), and Group-D (Zingerone treatment alone) and each group have six animals. Tellurium was given in Group-B and Group-C at the dose of $8.3 \mathrm{mg} / \mathrm{kg}$ bodyweight daily orally for 15 days, while Zingerone of $100 \mathrm{mg} / \mathrm{kg}$ body weight was given in Group-C as pre- and post-treatment orally for 15 days. Group-D was given alone Zingerone of $100 \mathrm{mg} / \mathrm{kg}$ bodyweight; orally for 15 days. Results revealed that tellurium administration significantly $(\mathrm{P}<0.001)$ increased the serum markers (ALP, BUN, Uric Acid and Creatinine) in Group-B as a compared to Group-A while the treatment with Zingerone significantly $(\mathbf{P}<\mathbf{0 . 0 0 1})$ decreased these elevated serum markers in Group-C as comparison to Group-B. There were no changes observed in the positive control (Zingerone administered Group-D). Thus, the present finding confirmed that the Zingerone plays a potential role in reducing nephrotoxicity against tellurium by abating elevated serum markers in rats.
\end{abstract}

Key words: Kidney function markers, Nephrotoxicity, Sodium tellurite, Zingerone

\section{Introduction}

Tellurium (Sodium tellurite) is white crystalline powder which considered as an important element of metallurgical industry such as corrosion resistance and glassware technologies etc. Its continuous industrial application and growth may create serious health problems to human in the future. Several types of research have been conducted to understand the mechanism of tellurium toxicity in the living organism and the rat model. Alam et al., (2014) studied the antibacterial toxicity of sodium tellurite against selected pathogens and found it most effective against Bacillus subtilis (B. subtilis), Proteus vulgaris ( $P$. vulgaris), and Staphylococcus aureus ( $S$. aureus) and he has also reported the toxicity of sodium tellurite against mosquito larvae Ades caspius and its lethal concentration $\left(\mathrm{LC}_{50}\right)$ value was evaluated to be 37.5ppm. Kaur et al., (2003) reported that sodium tellurite produces the neurotoxicity by reducing the lipid profile in cerebrum, cerebellum,

\section{Author's Address}

${ }^{1}$ Department of Pharmacology and Toxicology, College of Pharmacy, Jazan University, KSA.

${ }^{2}$ Department of Pharmaceutics, College of Pharmacy, Jazan University, Jazan KSA.

E-mail.: firozalam309@gmail.com and brainstem of mice whereas Safhi, (2018) presented that the tellurium administration also produces brain mitochondrial toxicity in mice. Tellurium toxicity on the liver is recently reported by present groups (Safhi et al., 2016) but still, there is not any investigation or reports are available on the nephrotoxicity which stimulates present interest to find out tellurium toxicity on kidney and its management.

Natural products derived from the plant for the treatment of diseases have proved that nature stands a golden mark to show the relationship between man and his environment. In search of newer and novel compound plant kingdom is the best source for the drug and discovery. Thus researches and utilization of natural product in treatment of different kind of disease increases every day. Zingerone is one of the popular active compounds presents in ginger (Zingiber officinale) and has a diverse pharmacological actions like antioxidant, anti-inflammatory, anti-cancer, lipolytic, antiemetic and anti-diabetic (Ahmad et al., 2015; Alam 2018, Anwer et al. 2019). Zingerone is a crystalline solid with the chemical formula $\left(\mathrm{C}_{11} \mathrm{H}_{14} \mathrm{O}_{3}\right)$, molecular weight $(194.22 \mathrm{~g} / \mathrm{mole})$ and sparingly soluble in 
water and its chemical structure is given in Figure 1 ( Monge et al., 1984). Safhi, (2018) determined that the Zingerone plays an important role in enhancing antioxidant enzymes, scavenging free radicals, and protecting brain mitochondria against tellurium toxicity. Alam et al., (2018) reported the therapeutic action of Zingerone against $\mathrm{CCl}_{4}$ induced liver toxicity in rats.

Thus, Zingerone was found to be effective in minimizing the variable toxicity problems including nephrotoxicity. Therefore, the present study is focused to evaluate the nephroprotective effect of Zingerone against tellurium induced nephrotoxicity in the rats.

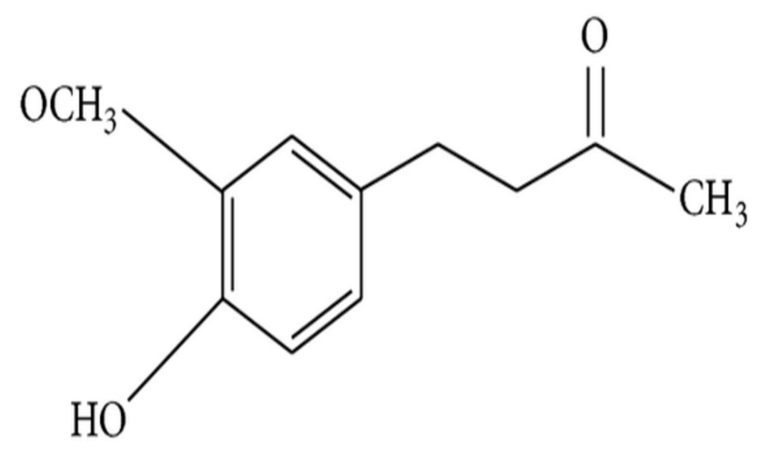

Figure. 1. Chemical Structure of Zingerone (4-(4hydroxy-3-methoxyphenyl) butan-2-one).

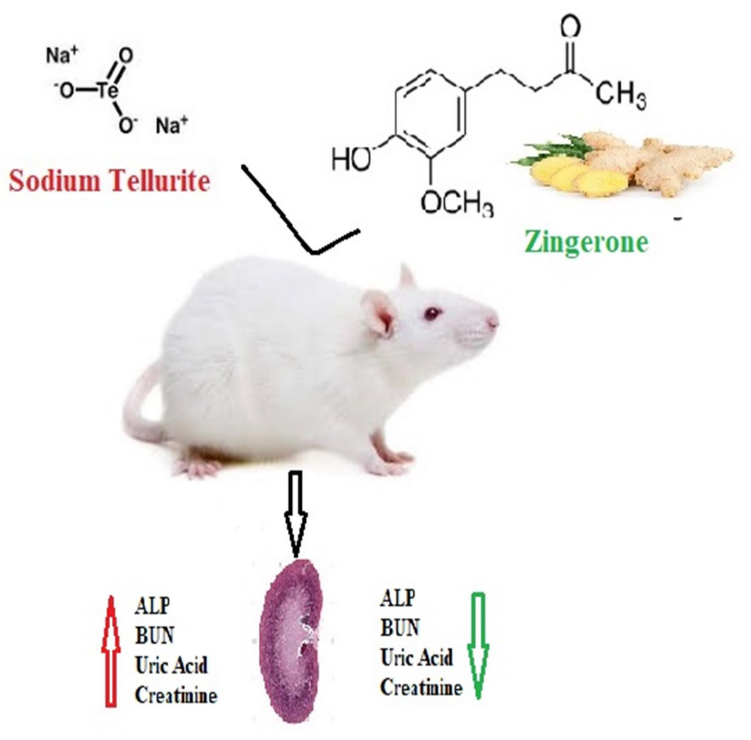

Fig 2. Graphical abstract

\section{Material and Methods}

\section{Chemicals and Kits}

Sodium tellurite, Zingerone (4-(4-Hydroxy-3methoxyphenyl)-2-butanone) were purchased from Sigma Aldrich, Co. St. Louis, Mo, USA. The important markers of kidney function tests were procured from Crescent Diagnostic Jeddah Saudi Arabia.

\section{Animals and Experimental Protocol}

The male rats $(180-220 \mathrm{~g})$ were obtained from the Medical Research Centre Animal House of Jazan University, Saudi Arab. All animals were kept in pharmacy college animal house under ideal laboratory condition $\left(24^{\circ} \mathrm{C}\right.$ and $12 \mathrm{hrs}$ light and dark cycle) and provided the standard diet and water. Care and treatment of animals were approved by the ethical committee and practices were performed according to the International Standard and Institutional Animal Care and Use Committee Guidelines (IACUC) (National Research Council, 1996). The rats were divided into four experimental groups with six animal each $(n=6)$ and details are as follow: Control group (Group-A; vehicle were given orally; for 15days),Toxic group [(Group-B were administered with Sodium tellurite at $1 / 10$ of $\mathrm{LD}_{50}$ dose of $8.3 \mathrm{mg} / \mathrm{kg}$ body weight; orally (p.o.) in saline; for 15 days) (Safhi et al., 2016)], Zingerone treated group [(Group-C served as pre and post-treated group; 2 days before till 15 days after administration of tellurium) of $100 \mathrm{mg} / \mathrm{kg}$ body weight) (Alam et al., 2014b)], and Zingerone control group (Group-D were given only Zingerone orally(p.o) at a dose of $100 \mathrm{mg} / \mathrm{kg}$ body weight for 15 days).

\section{Blood Collection and Serum Preparation}

On the $16^{\text {th }}$ day of experiments, the rats were sacrificed under anaesthesia and blood samples were withdrawn from fasted animals of each group. After collection of whole blood, it was kept at room temperature for $15-30 \mathrm{~min}$ to coagulate and then it was centrifuged at $1,000 \mathrm{~g}$ for $10 \mathrm{mins}$ in a refrigerated centrifuge. After that supernatant (serum) was taken for further biochemical analysis and kept under $4^{0} \mathrm{C}$ in freezer till complete biochemical analysis.

Kidney Functional Test (KFT) Markers

Kidney functional test markers such as alkaline phosphatase (ALP), blood urea nitrogen (BUN), uric acid and creatinine were measured by the 
standard procedure of Peake, 1988; Huston,1990; Buchanan,1965 and Roscoe, 1953 respectively. In the brief estimation of alkaline phosphatase (ALP), p-nitrophenyl phosphate (p-NPP) was used as a phosphatase substrate and detected at $405 \mathrm{~nm}$ by colorimetric procedure. In Uric acid estimation, uricase catalyses the oxidation of uric acid into allantoin and hydrogen peroxide. Further, in the presence of peroxidase, hydrogen peroxide reacts with 3,5-Dichloro-2-Hydroxy-Benzene sulfonic acid (DHBS) and form quinone imine dye, which was detected at $546 \mathrm{~nm}$. Blood urea nitrogen was estimated as the standard procedure of kits at $340 \mathrm{~nm}$. Creatine and p-creatine are converted nonenzymatically to the metabolite creatinine, which diffuses into the blood and is excreted out through the kidneys. It was estimated by using UV-vis spectrophotometer at $490 \mathrm{~nm}$.

\section{Results and Discussion}

The kidney is an important organ that helps in excretion of several chemicals or drugs and its metabolite from the body. Several drug and chemicals also induced acute kidney injury that causes severe health problem and death worldwide. Sodium tellurite accumulated in the liver, spleen, and kidney of human (Keall et al., 1946). Tellurium is eliminated via the urine, sweat and expired air in the form of dimethyl telluride (Amdur 1947, de Meio 1947, Steinberg et al., 1942). Tellurium is well known for a different kind of toxicity in animals such as liver toxicity (Safhi et al., 2016), neurotoxicity (Kaur et al., 2003), and carcinogenicity (Schroeder and Mitchener 1971) due to tellurium metabolite, dimethyl telluride which may be accountable for the high production of Reactive Oxygen Species(ROS) and oxidative stress in kidney tissue. As we know biochemical markers play an important role in the detection of risk, accurate diagnosis and improving clinical outcome. Thus, biomarkers evaluated as an indicator of normal biological, pathological and pharmacological actions to a therapeutic intervention. The important classical biomarkers for renal function are alkaline phosphatase, blood urea nitrogen, uric acid and creatinine that indicates the pathological condition of kidney. In this study, tellurium induces nephrotoxicity significantly $(\mathrm{P}<0.001)$ in rats by showing elevated classical kidney functional biochemical markers such as alkaline phosphatase, blood urea nitrogen, uric acid and creatinine in Group-B as compared to Group-A (Table-1). The rising serum markers are considered as one of the most important clinical indications of severity of necrosis due to the high production of free radicals by tellurium metabolite (dimethyl telluride). Thus, increase in ALP, BUN, Uric Acid and Creatinine activity due to injury of the brush border membrane of the renal tubular cells and leakage into blood indicated the renal function impairment and contrast induce nephrotoxicity. Previous reports also favour present study that repeated oral administration of sodium tellurite doses $(>0.5 \mathrm{mg} / \mathrm{kg}$ body weight) caused changes in the morphology of kidneys in rat and rabbits (El'nichnykh and Lenchenko 1971).

Table 1. Zingerone protects elevated kidney function marker in rat serum against tellurium induced nephrotoxicity

\begin{tabular}{|l|l|l|l|l|}
\hline Groups and Treatment & $\begin{array}{l}\text { ALP } \\
(\mathbf{u} / \mathbf{l})\end{array}$ & $\begin{array}{l}\text { BUN } \\
(\mathbf{m g} / \mathbf{d l})\end{array}$ & $\begin{array}{l}\text { Uric Acid } \\
(\mathbf{m g} / \mathbf{d l})\end{array}$ & $\begin{array}{l}\text { Creatinine } \\
(\mathbf{m g} / \mathbf{d l})\end{array}$ \\
\hline Group-A (Normal Control) & $80.93 \pm 5.62$ & $17.17 \pm 1.17$ & $5.04 \pm 0.87$ & $0.80 \pm 0.04$ \\
\hline Group-B (Tellurium Treated) & $194.17 \pm 4.07^{* * *}$ & $32.83 \pm 2.04^{* * *}$ & $13.05 \pm 0.96^{* * *}$ & $1.77 \pm 0.08^{* * *}$ \\
\hline Group-C (Tellurium+Zingerone) & $121.33 \pm 4.46^{\text {\#\# }}$ & $22.67 \pm 2.16^{\text {\#\# }}$ & $8.48 \pm 0.70^{\# \# \#}$ & $0.92 \pm 0.11^{\text {\#\# }}$ \\
\hline Group-D (Zingerone Treated) & $88.33 \pm 7.61^{\mathrm{ns}}$ & $19.50 \pm 1.87^{\mathrm{ns}}$ & $6.51 \pm 0.63^{\mathrm{ns}}$ & $0.82 \pm 0.06^{\mathrm{ns}}$ \\
\hline
\end{tabular}

Tellurium administration increased significantly ALP, BUN, Uric Acid and Creatinine in toxic group (Group-B) vs (Group-A) control group $\left({ }^{* * *} \mathrm{P}<0.001\right)$. Zingerone treatment reduced these levels significantly in Group-C vs Group-B ( $\left.{ }^{\# \#} \mathrm{P}<0.001\right)$ and no significant (ns) changes were noticed in Zingerone treated Group-D as compared to Group-A $\left({ }^{\mathrm{ns}} \mathrm{P}>0.05\right)$. All the values are represented in this table are mean $\pm \mathrm{SD}$ of six animals. 
Plant is an important source of medicine that plays an important role in the management of several kinds of disease control throughout the world since the ancient time. The use of medicinal plants not only for the therapeutic action but also as potential and nutritional material for maintaining the good health and conditions. Medicinal plants have provided a large number of potent drugs to fight the diseases in spite of advancement in synthetic drugs, some of the plant derived drugs still retained their importance and relevance. The strong belief that many medicinal plants are safe, free from side effect and environmental effects. People typically use fresh or dried ginger in cooking, and some time take ginger supplements for their possible health benefits since the ancient time (Mashhadi et al., 2013). Ginger have a potential antioxidants and other nutrients that help to prevent or treat several kind of disease like arthritis, inflammation and various types of infection. Ginger have potential an active constituent named Zingerone that play a major role in reducing the risk of diabetes, heart problem, cancer, severe infection and other health problems (Bilal Ahmad et al., 2015). In the present study Zingerone significantly $(\mathrm{P}<0.001)$ reduces these kidney function markers in Group- $\mathrm{C}$ as compared to Group-B which is depicted in the table (Table 1). It's only possible due to high antioxidant properties of Zingerone that suppressing the generation of free radicals and oxidative stress which protect the liver, kidney, heart and brain from damages (Tirkey et al., 2005; Jayakumar 2008). The present study indicated that the repeated exposure of tellurium slow down the kidney function and increases the levels of alkaline phosphatase, blood urea nitrogen, uric acid and creatinine in the blood, while the Zingerone treatment reduces significantly these markers in serum, and provided good protection against tellurium induced nephrotoxicity. Treatment with Zingerone alone in Group-D presented no significant $(\mathrm{P}>0.05)$ changes as compared to Group A. This indicates that Zingerone itself is not a toxic at this dose, therefore no significant elevation in above markers were observed.

\section{Conclusion}

The present study confirmed that tellurium induces the nephrotoxicity by enhancing the biochemical markers in serum might be through depleting the antioxidant enzymes in the tissue. In this study, Zingerone provides better protection against tellurium induced nephrotoxicity by the regulation of biochemical markers. Thus, in continuation of this study, there is further need to investigate and explore the oxidative stress, inflammatory cytokines, apoptosis and histopathological changes in the tissue in order to confirm the tellurium induced toxicity in rat's kidney and its protection with Zingerone.

\section{Acknowledgements}

I am thankful to Deanship of Scientific Research, Jazan University KSA for providing the financial support under the $9^{\text {th }}$ scientific forum grant no. FR6-55.

\section{Discloser of Statements}

This is to acknowledge that there is no financial interest or benefits have arisen directly or indirectly from any authors in this research.

\section{References}

Ahmad, B., Rehman M.U, Amin, I., Arif, A., Rasool, S., Bhat, S.A., Afzal, I., Hussain, I., Bilal, S., Mir, M.U., 2015. A Review on Pharmacological Properties of Zingerone (4-(4Hydroxy-3-methoxyphenyl)-2-butanone). Scientific World Journal, 2015:816364.

Ahmad, B., Rehman, M. U., Amin, I., Arif, A., Rasool, S., Bhat, S.A., Afzal, I., Husanin, I., Bilal, S., Mir, M.R.A. 2015. Review on pharmacological properties of Zingerone (4-(4-hydroxy-3methoxyphenyl)-2-butanone).

The Scientific World Journal, 2015: 1-6.

Alam, M. F., Safhi, M.M., Sivakumar, S.M., Anwer, T., Khan, G., Islam, F. 2014a. Anti bacterial toxicity of Sodium tellurite (ST) against selected bacterial strains. Research Journal of Pharmcy and Technology, 7(5): 499-501.

Alam, M.F. 2014b.Toxicity of sodium tellurite $\left(\mathrm{Na}_{2} \mathrm{TeO}_{3}\right)$ against Aedes caspius larvae in Gizan, Southwestern region, Kingdom of Saudi Arabia, Environment Conservation Journal, 15(3): 29-33.

Alam, M.F., Safhi, M.M., Anwer, T., Siddiqui, R., Khan, G., Moni, S.S. 2018. Therapeutic potential of Vanillylacetone against $\mathrm{CCl} 4$ induced hepatotoxicity by suppressing the serum marker, oxidative stress, inflammatory cytokines, and apoptosis in Swiss albino mice. Experimental and Molecular Pathology, 105 (1): 81-88. 
Alam, M.F. 2018. Neuroprotective effects of Zingerone against carbon tetrachloride $(\mathrm{CCl} 4)$ induced brain mitochondrial toxicity in Swiss albino mice. Journal of Applied and Natural Sciences, 10 (2): 548-552.

Amdur, M.L. 1947. Tellurium. Accidental exposure and treatment with BAL in oil. Occup Med. 3: 386-391.

Anwer, T., Alkarbi, Z.A., Hassan Najmi, A., Alshahrani, S., Siddiqui, R., Khan, G., Alam, M.F. 2019. Modulatory effect of Zingerone against STZ-nicotinamide induced type-2 diabetes mellitus in rats. Achieves of Physiology and Biochemistry, 2019:1-7.

Buchanan, M. J., Isdale, I.C., Rose, B.S.1965. Serum uric acid estimation chemical and enzymatic methods compared. Annals of the Rheumatic Diseases. 24(3):285288. doi:10.1136/ard.24.3.285.

De Meio, R.H. 1947. Tellurium. II. Effect of ascorbic acid on the tellurium breath. Journal of Industrial Hygiene and Toxicology, 29: 393-395.

El'nichnykh, L.N., Lenchenko, V.G. 1971. Histomorphological changes in animal organs during poisoning with tellurium compounds. Toxicology, 74: 97306.

Hosten, A.O. 1990. BUN and Creatinine. In: Walker HK, Hall WD, Hurst JW, editors. Clinical Methods: The History, Physical, and Laboratory Examinations. 3rd edition. Boston: Butterworths; Chapter 193.

Kaur, P., Yousuf, S., Ansari, M.A., Siddique, A., Ahmad, A.S., Islam, F.2003. Tellurium-induced dose-dependent impairment of antioxidant status: differential effect in cerebrum, cerebellum, and brain stem of mice. Biological Trace Element Research, 94: 247-258.

Keall, J.H.H., Martin, N.H., Tunbridge, R.E. 1946. A report of three cases of accidental poisoning by sodium tellurite. British Journal of Industrial Medicine, 3: 175-176.

Mashhadi, N. S., Ghiasvand, R., Askari, G., Hariri, M., Darvishi, L., Mofid, M. R. 2013. Anti-oxidative and anti- inflammatory effects of ginger in health and physical activity: review of current evidence. International journal of preventive medicine, 4(Suppl 1), S36-S42.

Monge, P., Solheim, E., Scheline, R.R.1984. Dihydrochalcone metabolism in the rat: Phloretin. Xenobiotica, 14(12): 917924.

National, Research Council, 1996. Guide for the Care and Use of Laboratory Animals, 7th ed. National Academy Press, Washington DC.

Peake, M.J., Pejakovic, M., White, G.H. 1988. Quantitative method for determining serum alkaline phosphatase isoenzyme activity: estimation of intestinal component. Journal of Clinical Pathology, 41(2):202206.

Roscoe, M.H.1953. The estimation of creatinine in serum. Journal of Clinical Pathology, 6(3):201-207.

Safhi, M.M. 2018. Nephroprotective Effect of Zingerone against $\mathrm{CCl}_{4}$-Induced Renal Toxicity in Swiss Albino Mice: Molecular Mechanism. Oxidative Medicine and Cellular Longevity, 2018: 1-7.

Safhi, M.M., Alam, M.F., Khuwaja, G., Islam, F., Hussain, S., Fageeh, M.M., Anwer, T., Islam F. 2016. Repeated exposure of Sodium Tellurite on the rat liver and on the potential mechanisms of the metalloid-induced hepatotoxicity. Acta Poloniae Pharmaceutica - Drug Research, 73(3):675-682.

Schroeder, H.A., Mitchener, M. 1971. Selenium and tellurium in rats: effect on growth, survival and tumors. Journal of Nutrition, 101: 1531-1540.

Steinberg, H. H., Massari, S.C., Miner, A.C., Rink, R. 1942. Industrial exposure to tellurium: atmospheric studies and clinical evaluations. Journal of Industrial Hygiene and Toxicology, 24: 183-192. 